\title{
EFFICIENCY AND EFFECTIVENESS ANALYSIS OF SUGARCANE MILLING AT MADUKISMO SUGAR FACTORY OF YOGYAKARTA, INDONESIA
}

\author{
Setyaningrum Widyadhari Febriani ${ }^{\star}$, Postgraduate Student \\ Ekowati Titik, Kristanto Budi Adi, Lecturers \\ University of Diponegoro, Indonesia \\ *E-mail: febri ani03@yahoo.co.id
}

\begin{abstract}
The research is aimed to measure milling activities technical efficiency level and equipment effectiveness at Madukismo Sugar Factory. The research method used DEA (Data Envelopment Analysis) with input assumption oriented to measure efficiency scores from observed each milling year and Overall Equipment Effectiveness method to measure equipment effectiveness. The result showed 2 sugarcane milling years has operated efficiently and 5 sugarcane milling years has not operated efficiently yet (inefficient). Efficiency calculation using Variable Return to Scale (VRS) assumption produced average efficiency value 1.000. Efficiency was reached by all milling year from 2012 to 2017 . On the contrary, observation from SE value showed 2 people have reached full efficiency. It means that DMU has reached efficiency either from CRS assumption or VRS while the other 5 milling years is still grouped in inefficiency category.
\end{abstract}

\section{KEY WORDS}

Efficiency, effectiveness, sugarcane mill, production.

In the last decade, sugarcane industry experiences a decrease because of various existed problem. The decrease in the sugarcane industry is caused by on-farm and off-farm factors. The average production of sugarcane is below $80 \%$ per ha with a yield below $8 \%$. The obstacles from off-farm side come from less efficiency and effectiveness of sugarcane factories performance. The less efficiency and effectiveness of sugarcane factories performance allegedly caused by the old age of equipment, so, its performance was less maximal. Therefore, the efficiency of production factor on milling activity and equipment efficiency level on off-farm level needs to be reviewed to decide the further step for improving sugarcane production widely.

\section{LITERATURE REVIEW}

Efficiency is an action to maximize a result by using minimum capital includes employee, material, and equipment (Stoner, 2010). The efficiency is a ratio or comparison between input and output.

Everything aimed to input and how the comparison numbers are obtained will depend on the purpose of measurement rod usage. To make it simple, according to Nopirin (2014), efficiency can be meant free from wasteful.

Nakajima (1989) defined OEE (Overall Equipment Effectiveness) as a matrix or measure to evaluate equipment effectiveness. OEE tried to identify production loss and other hidden and indirect cost which give a high contribution to total production cost. The losses are formed by Huang et al, (2003) as a function of the connected exclusive component such as Availability, Performance, and Quality.

Williamson (2006) also explained the benefit of OEE is its ability to measure effectiveness totally (complete, inclusive, whole) from an equipment's performance to do a planned duty. It is also measured from actual data connected to availability, performance efficiency, and product quality. Then, the other information from OEE is used to identify and classify the reason for equipment's low performance. 
DEA method was developed for the first time by Charnes et al. (1978) to evaluate Decision Making Unit (DMU) relative efficiency in an organization by giving integrity to input and output.

Table 1 - Efficiency Value of Milling at Madukismo Sugar Factory

\begin{tabular}{lllll}
\hline \hline No & Milling year & TE CRS & TE VRS & SE \\
\hline \hline 1 & 2011 & 0.918 & 1.000 & 0.918 \\
2 & 2012 & 1.000 & 1.000 & 1.000 \\
3 & 2013 & 1.000 & 1.000 & 1.000 \\
4 & 2014 & 0.927 & 1.000 & 0.927 \\
5 & 2015 & 0.951 & 1.000 & 0.951 \\
6 & 2016 & 0.982 & 1.000 & 0.982 \\
7 & 2017 & 0.855 & 1.000 & 0.855 \\
\hline & Average & 0.948 & 1.000 & 0.948 \\
& Minimal Value & 0.855 & 1.000 & 0.855 \\
& Maximal Value & 1.000 & 1.000 & 1.000 \\
& Efficient Amount & 2 milling year & 7 milling year & 2 milling year \\
& Inefficient Amount & 5 milling year & - & 5 milling year \\
\hline
\end{tabular}

Table 2 - Availability Value, Performance, Quality and Overall Equipment Effectiveness

\begin{tabular}{llllll}
\hline \hline No & Year & Availability Value & $\begin{array}{l}\text { Performance } \\
\text { Value }\end{array}$ & $\begin{array}{l}\text { Quality } \\
\text { Value }\end{array}$ & OEE Value \\
\hline 1 & 2008 & 0.95 & 0.95 & 0.70 & 63.25 \\
2 & 2009 & 0.97 & 0.97 & 0.86 & 80.40 \\
3 & 2010 & 0.91 & 0.92 & 0.67 & 56.30 \\
4 & 2011 & 0.98 & 0.98 & 0.69 & 66.77 \\
5 & 2012 & 0.97 & 0.97 & 0.69 & 64.30 \\
6 & 2013 & 0.95 & 0.95 & 0.74 & 66.63 \\
7 & 2014 & 0.93 & 0.96 & 0.85 & 76.21 \\
8 & 2015 & 0.97 & 0.97 & 0.72 & 67.96 \\
9 & 2016 & 0.89 & 0.89 & 0.61 & 48.43 \\
10 & 2017 & 0.94 & 0.95 & 0.67 & 59.62 \\
\hline \multicolumn{2}{r}{} \\
\hline
\end{tabular}

Table 3 - Milling Efficiency Value at Madukismo Sugar Factory

\begin{tabular}{llll}
\hline \hline Efficiency Value & Amount of DMU & Percentage & Efficiency Scale \\
\hline & $\ldots$ Milling year... & $\ldots \% \ldots$ & \\
Total sample & 7 & 100 & 0.948 \\
Decreasing return to scale (DRS) & - & - & - \\
Constant return to scale (CRS) & 2 & 28.57 & 1.000 \\
Increasing return to scale (IRS) & 5 & 71.43 & 0.927 \\
\hline
\end{tabular}

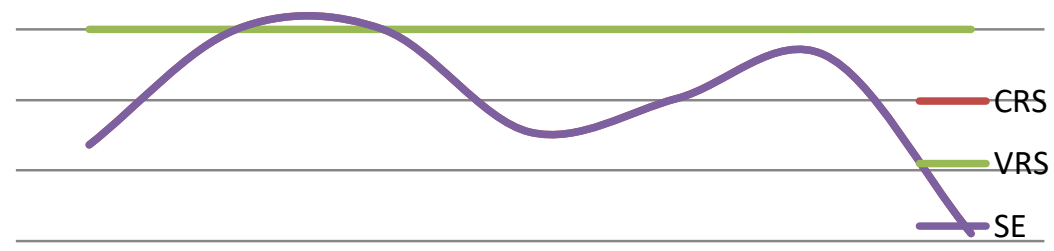

Figure 1 - Efficiency Graphic at Madukismo Sugar Factory

On DEA analysis contains three steps that were done, they are:

- Table of Efficiencies (Radial). The analysis showed which one the most efficient Economic Activity Unit (EAU) is. Efficiency is showed by the optimum value of purpose function which is developed from Linear Programming (LP). Function 
purpose value $100(100 \%)$ means the EKU is efficient while the other which has a value less than 100 is inefficient;

- Table of Peer Units. The table was used to determine if an EAU is not efficient so, will be showed how to reach perfect efficiency level (to reach 100) by looking peer (EAU which being an orientation to meet efficiency level);

- Table of Target Values. The analysis was used to determine how many percent efficiencies have been reached for every EAU either from every input structure or output structure. If actual value equal with the target value, efficiency for every input or output has been reached. On the other hand, if the value between actual and target is not equal; efficiency has not been reached yet.

\section{METHODS OF RESEARCH}

The basic method used is a descriptive method to tell problem-solving today based on data, then, the data is analyzed and interpreted (Narbuko dan Achmadi, 2007).

The research was held at Madukismo Sugar Factory, Yogyakarta. Efficiency milling analysis used the last 7 milling years data. As for equipment effectiveness analysis used the last 10 milling years data. The difference amount of data taking was caused by availability data at Madukismo Sugar Factory.

The method analyses the efficiency of input usage in milling activity using analysis tool DEA (Data Envelopment Analysis). Data Envelopment Analysis (DEA) method is created as a working evaluation tool for an activity which needs one input or more and produce a kind of output or more.

Simply, measurement is explained by the ratio between output and input which is an efficiency or productivity measurement unit that can be explained partially (Coper, 2002).

The basic efficiency used in DEA is a total input and total output ratio:

$$
\text { Efficiency }=\frac{\text { Output }}{\text { Input }}
$$

The symbol in the formula is used $X$ and $Y$ to represent input and output, $i$ and $j$ to represent the special input and output. So, $X_{1}$ is an input number-i and yj is an output number-j on decision-maker unit / DMU. Total input is represented by I and total output is represented by $\mathrm{J}$, which $\mathrm{I}, \mathrm{J}>0$. Mathematically, the formula can be pictured as shown below (Ramanathan, 2003):

$$
\text { Virtual Input }=\sum_{\mathrm{i}=1}^{\mathrm{I}}\left(\mathrm{u}_{\mathrm{i}} \mathrm{k}_{\mathrm{i}}\right)
$$

By ui is a quality of input xi during accumulation process, for output can be pictured like showed below:

$$
\text { Virtual Output }=\sum_{\mathrm{j}=1}^{\mathrm{J}}\left(\mathrm{v}_{\mathrm{j}} \mathrm{y}_{\mathrm{j}}\right)
$$

By vj is a quality of an input yj during accumulation process. Based on virtual model of input and output above, so, the efficiency can be defined by a formula below:

$$
\text { Efficiency }=\frac{\text { Virtual Output }}{\text { Virtual Input }}=\frac{\sum_{\mathrm{j}=1}^{\mathrm{J}}\left(\mathrm{v}_{\mathrm{j}} \mathrm{y}_{\mathrm{j}}\right)}{\sum_{\mathrm{i}=1}^{\mathrm{l}}\left(\mathrm{u}_{\mathrm{i}} \mathrm{k}_{\mathrm{i}}\right)}
$$


If there is a DMU which will be compared from the efficiency level, so, the linear fraction form of DEA program can be shown in the formula below:

Subject to:

$$
E m=\frac{\sum_{i=I}^{J}\left(v_{j m} y_{j m}\right)}{\sum_{i=I}^{J}\left(u_{i m} k_{i m}\right)}
$$

$$
\begin{gathered}
0 \leq \frac{\sum_{i=I}^{J}\left(v_{j m} y_{j m}\right)}{\sum_{i=I}^{J}\left(u_{i m} k_{i m}\right)} \leq 1 n=1,2, \ldots . N \\
v_{j m} u_{j m} \geq 0 i=1,2, \ldots . I j=1,2, \ldots J
\end{gathered}
$$

Where: $E m$ = efficiency DMU number-m; yjm = output number-j for DMU number-m; vjm = output quality value; xim = input number-i for DMU number-m; uim = input quality value; yjn and xin are output number-j and input number-i for each DMU number-n, $n=1,2, \ldots, N$. And $m$ is a part of $n$.

Effectiveness analysis was measured using the Overall Equipment Effectiveness (OEE) method. OEE tried to identify production loss and other hidden and indirect cost loss which have a contribution to total production cost.

The losses are formulated by Huang et al, (2003) as a function of several exclusive connected components such as availability, performance, and quality. Williamson (2006) also explained the advantage of OEE is its ability to measure effectiveness totally (complete, inclusive, overall) of equipment performance to do a planned duty and measured by actual data connected with availability, performance efficiency, and quality of the product.

Then, information from OEE is used to identify and classify the reason for equipment's low performance.

Calculation of OEE element is done by formulas below:

Availability:

$$
\begin{gathered}
\frac{\text { Run Time }}{\text { Total Time }} \times 100 \% \\
\frac{\text { Amount of Milling Day }}{\text { Amount of Milling Day }+ \text { Amount of stop milling day }} \times 100
\end{gathered}
$$

Performance:

$$
\begin{gathered}
\frac{\text { Total Count }}{\text { Target Counter }} \times 100 \% \\
\frac{\text { exclusive milling capacity }}{\text { mounted milling capacity }} \times 100 \%
\end{gathered}
$$

Quality:

$$
\begin{gathered}
\frac{\text { Good Count }}{\text { Total Count }} \times 100 \% \\
\frac{\text { GKP product realization }}{\text { Total milled sugarcane } x \text { sugarcane Pol }} \times 100 \%
\end{gathered}
$$

Overall Equipments Effectiveness:

Availability x Performance $\times$ Quality 


\section{RESULTS AND DISCUSSION}

The efficiency of milling activity at Madukismo sugar factory was analyzed by DEA analysis method. Assumptions used on the DEA measurement are Constant Return to Scale (CRS) and Variable Return to Scale (VRS). The inputs used are harvest wide, amount of sugarcane, yield, permanent employee, and non-permanent employee during the last 7 years, while output used, is sugar production.

Efficiency scale analysis was done by comparing between DEA-CRS score and DEAVRS efficiency's score which if both ratio equal to 1 it shows full efficiency scale. On the contrary, if both ratios are less than 1 it means inefficiency happened.

But if the scale of the efforts does not show Return to Scale (RTS) position from observed DMU whether operated on Increasing Return to Scale (IRS) or Decreasing Return to Scale (DRS). IRS means input increasing by amount $1 \%$ will increase $1 \%$ more output. On the contrary, DRS mean input increasing $1 \%$ will increase less $1 \%$ output.

Average sugarcane milling efficiency using Constant Return to Scale (CRS) assumption is 0.948 . The calculation results in data 2 milling years of efficient operation and 5 milling years of inefficient operation.

The lowest efficiency value is 0.855 in 2017 and the highest value 1.000 was reached in 2012 and 2013. Efficiency calculation using Variable Return to Scale (VRS) results average efficiency value 1.000. Efficiency was reached by overall milling year from 20122017 while observed from SE value showed 2 people reached full efficiency. It means the DMU has reached efficiency either CRS or VRS. While the other 5 milling year still be grouped on inefficiency category.

Calculation result using DEA method shows no milling activity on Decreasing Return to Scale (DRS) position. 2 milling years on constant return to scale position or optimal scale are 2012 and 2013 milling year by efficiency scale 1.000, while the other 5 milling years are categorized to increasing the return to scale or sub-optimal scale by efficiency scale 0.927 .

The analysis result means sugarcane milling activity at Madukismo Sugar Factory today still possible for adding more input to reach efficiency.

The inefficiency of milling activity at Madukismo Sugar Factory still can be improved according to efficiency presented in previous years are 2012 and 2013. Beside becomes a reference for improvement, 2012 and 2013 milling activity can be a reference for the next milling year to reach efficiency.

Effectiveness analysis of sugar factory was measured using the Overall Equipment Effectiveness (OEE) method. A sugar factory called has reached effectiveness on machine and equipment performance if its OEE value has reached $\geq 85$. Based on the OEE value calculation in OEE table can be concluded that during the last 10 years Madukismo Sugar Factory has never reached effectiveness yet.

Even average equipment valued 64.99 which can be called still far from effective. The most effective equipment was reached in 2009 by effectiveness value 80.4 and the lowest performance of equipment was shown in 2016 by value only 48.43 .

Low effectiveness of sugar factory was caused by the old age of the machine. Madukismo Sugar Factory was established since 1955. Since it was established, the factory just repairs broken equipment or replacing the part which unable to repair.

By observing the equipment's performance effectiveness at Madukismo Sugar Factory, revitalization can be the key to improve the machine's performance.

\section{CONCLUSION}

The average efficiency of sugarcane milling using Constant Return to Scale (CRS) is 0.948. The calculation resulted 2 milling years has operated efficiently and 5 milling years has not operated efficiently yet. The lowest value 0.855 obtained by 2017 milling year and the highest value has reached by 2012 and 2013 milling years. The efficiency calculation using Variable Return to Scale (VRS) earned average efficiency value 1.000. Efficiency reached by all milling years from 2012 to 2017. On the other hand, the SE value showed 2 
people have reached full efficiency. It means the DMU has reached a good efficiency either in CRS assumption or VRS. The other 5 milling years still categorized as inefficient.

Equipment and machine performance's effectiveness during the last 10 years at Madukismo Sugar Factory has never met effectiveness yet. The average value of equipment effectiveness was only valued at 64.99. The most effective year of factory equipment is in 2009 by effectiveness value 80.4 and the lowest effectiveness value was obtained in 2016 by effectiveness value only 48.43 .

\section{REFERENCES}

1. Charnes, A., W.W. Cooper and E. Rhodes. (1978). Measuring the efficiency of decision making units. European Journal of Operations Research, 2:429-444.

2. Cooper, William W., Seiford, L.M., Tone, K., (2006). Data Envelopment Analysis A Comprehensive Text with Models, Applications, References and DEA-Solver Software Second Edition. Springer Science+Business Media, LLC. United States of America.

3. Huang, S. H., Dismukes, J. P, Mousalam, A., Razzak, R. B., Robinson, D.E. (2003). Manufacturing Productivity Improvement Using Effectiveness Metrics and Simulation Analysis, International Journal of Production Research, 41(3): 513-527.

4. Nakajima, S. (1988). Introduction to TPM, Productivity Press, Cambridge, MA.

5. Narbuko, Cholid dan H. Abu Achmadi. (2007). Research Method. Bumi Aksara. Jakarta.

6. Nopirin. (2014). Introduction to Economics. Mikro Makro. BPFE. Yogyakarta.

7. Ramanthan, R. (2004). An Introduction to Data Envelopment Analysis: A Tool for Performance Measurement. Sage Publications Inc. New Delhi.

8. Williamson, R. M. (2006). Using Overall Equipment Effectiveness: The Metric and the Measures, Strategic Work Systems, Inc, Columbus. 